\title{
Unemployment and smoking: does psychosocial stress matter?
}

\author{
R De Vogli, M Santinello
}

Tobacco Control 2005;14:389-395. doi: 10.1136/tc.2004.010611

See end of article for authors' affiliations

.....................

Correspondence to: Roberto De Vogli,

International Centre for Health and Society, Department of

Epidemiology and Public Health, University College of London, 1-19

Torrington Place, London

WCIE 6BT, UK

r.devogli@úcl.ac.uk

Received 18 November 2004

Accepted 8 June 2005

\begin{abstract}
Aim: Research indicates that cigarette smoking is strongly associated with unemployment. However, little is known regarding the underlying mechanisms explaining this relationship. The aim of this study is to examine the role of psychosocial factors as potential mediators between unemployment and smoking. Participants: 4002 non-institutionalised, civilian adults living in the Veneto region of Italy.

Design: The study was based on a computer assisted telephone interview (CATI). Linear by linear association tests were used to examine bivariate associations between unemployment, psychosocial factors, and smoking. Logistic regression models were developed to analyse the relationship between unemployment and smoking when adjusting for psychological factors.

Results: The odds of smoking among the unemployed was 2.78 times (95\% confidence interval (Cl) 1.68 to 4.62) greater than that of higher managers and professionals controlling for demographic factors. The relationship between unemployment and smoking weakened (odds ratio $2.41,95 \% \mathrm{Cl} 1.43$ to 4.05 ) when psychosocial factors were entered into the analysis. The odds of the inability to control important things in life was 1.39 times $(95 \% \mathrm{Cl} 1.11$ to 1.75$)$ greater, and the odds of emotional isolation was 1.45 times (95\% Cl 1.06 to 1.99$)$ greater, among smokers compared to non-smokers controlling, for all other factors. Conclusions: Given that the data were cross sectional, firm conclusions cannot be drawn regarding the causal pathway connecting unemployment and smoking. However, this study suggests that psychosocial factors such as the inability to control and emotional isolation may be plausible mediators for the relationship.
\end{abstract}

C igarette smoking is considered one of the most serious risk factors for chronic diseases worldwide. In populations where smoking has been common for many decades, tobacco use accounts for a large proportion of mortality. Overall, it is thought to be responsible for $26.3 \%$ of deaths and $17.1 \%$ of disability adjusted life-years (DALYs) among males and $9.3 \%$ of deaths and $6.2 \%$ of DALYs among females in industrialised nations. Current smoking patterns are estimated to account for 2.4 million deaths each year in the same area. ${ }^{1}$ Cigarette smoking increases risk for lung cancer, upper aero digestive cancer, several other cancers, heart disease, stroke, chronic respiratory diseases, and a number of other medical conditions. It is responsible for approximately $90 \%$ of lung cancer in men and about $70 \%$ of lung cancer among women. ${ }^{1-3}$ The attributable fractions for chronic respiratory diseases and cardiovascular diseases are $56-80 \%$ and $22 \%$, respectively. ${ }^{1}$

Several studies have indicated that smoking is associated with unemployment. ${ }^{4-9}$ Although the relationship is two way, evidence from longitudinal cohort studies demonstrated that even after controlling for "selection" (for example, smoking at the beginning of the study) and low socioeconomic status before unemployment, an effect of unemployment on smoking remains. ${ }^{8}{ }^{10}$ The scientific debate is open to understand why this health behaviour is influenced by unemployment. Promising mediators that may explain the behavioural modulating effect of unemployment are psychosocial factors. According to the psychosocial hypothesis, smoking is affected by feelings of stress, low control, and social isolation affecting lower occupational classes that are disproportionately exposed to adverse social and economic stressors (for example, financial strain, stigma, loss of social roles) compared to other occupational classes. Thomas and colleagues showed that transitions to unemployment are associated with psychological distress because of changes in subjective financial circumstances. ${ }^{11}$ Smoking is seen as a way of coping with stressful and uncontrollable social and economic problems in order to get short term stress relief. ${ }^{12}$

The relationship between psychological stress and smoking has been well documented in the literature. A study conducted by Metcalfe and colleagues ${ }^{13}$ found that higher levels of stress were associated with smoking a greater number of cigarettes. A study of the US adult population investigating individual responses to stress reported that $8.7 \%$ smoked cigarettes. ${ }^{14}$ Of course, there is also evidence that smoking can influence the levels of stress of individuals. A frequent explanation for smoking as a stress reliever is that nicotine reduces anxiety and tension. ${ }^{15}$

Another important psychosocial factor related to smoking is social support. Social relations seem to cushion the individuals from life events making them less exposed to feelings of stress, powerlessness, and loss of control. ${ }^{16}$ Conversely, social exclusion caused by long term unemployment is an important risk factor for low self esteem and mental health problems. ${ }^{17}$ It is also an important determinant of smoking. A recent study from Canada found that, among especially marginalised populations, self mastery and social support were significantly lower among smokers compared to non-smokers. ${ }^{18}$

In the present study we analyse the relationship between unemployment and smoking. We are also interested in examining the role of psychosocial factors as potential mediators for the relationship.

Abbreviations: BRFSS, behavioural risk factor surveillance system; DALYs, disability adjusted life-years; HDSS, Health Determinants Surveillance System; NS-SEC, National Statistics Socio Economic Classification 


\section{METHODS}

The study is based on the analysis of the 2003 Health Determinants Surveillance System (HDSS), a cross sectional telephone survey of civilian, non-institutionalised, adults living in the Veneto region of Italy. DOXA, an Italian research firm that specialises in statistical research and large scale sample surveys, was assigned the task of carrying out telephone interviews for the HDSS project. Interviews lasted about 20 minutes and were conducted in Italian.

The sampling strategy involved two phases. In the first phase, random digit dialling was used to select households in Veneto. The sample of working telephone numbers was stratified, using the seven provinces of Veneto as strata. Low density populated provinces were over sampled using a higher sampling fraction to limit sampling error. In the second phase, a quota sampling strategy was used to select respondents within the household with age, sex, educational attainment, employment status, and place of birth as quota controls. Only one respondent per household was interviewed.

A total of 4002 subjects were interviewed and the response rate was approximately $57 \%$. In order to adjust for potential sources of error, sampling weights were attached to each survey record. Sampling weights accounted for three factors: (1) geographic substrata per province to compensate for the over sampling of low density population provinces; (2) number of adults per household; (3) under-representation of unemployed people in the sample compared to the census data for 2001 of the Veneto region. Weights were rescaled so that the average weight was 1.0. This allowed matching the final sample size of 4002 subjects without inflating the statistical significance tests.

Unfortunately, information on refusals is limited, especially because the interview was anonymous. The Italian Personal Data Protection Act prevents the identification and reporting of information on refusals, therefore it was not possible to keep track of their demographic and socioeconomic characteristics. In order to partially bridge this information gap, interviewers and interview supervisors delivered written reports with regard to the demographic characteristics of interviews and refusals. According to their reports, and correspondence with interviewer supervisors, most refusals dropped out at the very beginning of the interview. Very few subjects who started being interviewed did not complete the interview. Records of interviewers showed that most refusals were predominantly males of younger age.

\section{Measures of interest \\ Cigarette smoking}

Cigarette smoking was measured by three questions to distinguish between those who were current smokers, exsmokers and those who had never smoked. A first question asked respondents to state if during their entire life they smoked at least 100 cigarettes. They were also asked to state if, at the time of the survey, they smoked cigarettes every day, some days, or not at all. Current smokers were defined as persons who reported smoking at least 100 cigarettes during their lifetime and who smoked some days or every day at the time of the survey. Former smokers were defined as persons who reported having smoked at least 100 cigarettes during their lifetime, but did not smoke at the time of interview. Questions were adapted from the behavioural risk factor surveillance system (BRFSS). ${ }^{19}$

\section{Stress}

Psychological stress in the HDSS questionnaire was assessed using a brief version of the perceived stress scale ${ }^{20}$ comprising the following four items: (1) In the last month, how often have you felt confident about your ability to handle your personal problems?; (2) In the last month, how often have you felt that things were going your way?; (3) In the last month, how often have you felt that you were unable to control the important things in your life?; (4) In the last month, how often have you felt difficulties were piling up that could not be overcome?. Alternatives were the following: never (0), almost never (1), sometimes (2), fairly often (3), and very often (4). An overall measure of stress was obtained by reversing the scores of the two positively stated items, with high score indicating a higher level of stress (range 016). However, given the low reliability coefficient of the scale (Cronbach's $\alpha=0.47$ ), the four stress items were considered singly.

\section{Social support}

The level of social support was assessed through two single items on emotional support ("Can you count on anyone to provide you with emotional support (talking over problems and helping you to make a difficult decision)?") and instrumental support ("When you need some extra help, can you count on anyone to help you with daily tasks like grocery shopping, house cleaning, cooking, telephoning, giving you a ride?"). The response for the first item is dichotomous (yes or no): the second item is followed by 11 potential sources that could provide support, and a count is made of the affirmative responses. ${ }^{21}$ Sources of support were: spouse, daughters, sons, siblings, other relatives, neighbours, co-workers, church members, club members, professionals, and other friends.

\section{Occupational class}

In order to assess respondents according to their occupational class, we used an Italian adaptation of the National Statistics Socio Economic Classification (NS-SEC), ${ }^{22}$ the classification system of the UK's Office for National Statistics. The NS-SEC classifies people's occupations on the basis of employment relations and conditions, and it is now widely adopted in both the UK and other European countries. ${ }^{23}$ The eight category NS-SEC includes the following social classes: higher managers and professionals (for example, sales managers of large organisations, lawyers, higher education teaching professionals), lower managerial and professionals (for example, marketing managers of small organisations, public services associate professionals), intermediate occupations (for example, accounts and wage clerks, database assistants), small employers (for example, shopkeepers and wholesale retailers, self employed electricians), lower supervisors, craft and related occupations (for example, supervisors in foundries, printers), semi-routine occupations (for example, care assistants, glass process operatives), and routine occupations (for example, sewing machinists, cleaners) and the unemployed. People who were retired, unable to work, in the civil service, students, housekeepers not in the workforce, and those providing inadequate descriptions $(\mathrm{n}=923)$ were excluded from the NS-SEC.

\section{Demographics}

Demographic measures included respondents' sex, age, place of birth, and marital status. Information regarding the area of residence of respondents was automatically provided by the CATI system. Moreover, information was gathered regarding educational attainment, car ownership, residential density, and housing tenure.

\section{Statistical analysis}

Data analyses were performed using SPSS 11.0. ${ }^{24}$ First, we analysed the distributions of occupational class, psychosocial factors, and smoking by sex. Linear by linear association tests 
Table 1 Distribution of characteristics of interest of the study population by sex

\begin{tabular}{|c|c|c|c|c|c|}
\hline & $\mathbf{n}$ & $\begin{array}{l}\text { Total } \\
\% \text { or mean }\end{array}$ & $\begin{array}{l}\text { Males } \\
\% \text { or mean }\end{array}$ & $\begin{array}{l}\text { Females } \\
\% \text { or mean }\end{array}$ & p Value \\
\hline Sex & 4002 & 100.0 & 47.6 & 52.4 & 0.01 \\
\hline Mean (SD) age (years) & 4002 & $45.7(16.8)$ & $44.9(16.9)$ & $46.4(16.8)$ & NS \\
\hline \multicolumn{6}{|l|}{ Smoking } \\
\hline Smokers & 889 & 22.2 & 26.2 & 18.6 & 0.01 \\
\hline Ex-smokers & 981 & 24.5 & 34.5 & 15.2 & 0.01 \\
\hline Never smokers & 2132 & 53.3 & 39.3 & 65.9 & 0.01 \\
\hline \multicolumn{6}{|l|}{ NS-SEC occupational class } \\
\hline Higher managers and professionals & 192 & 4.8 & 7.9 & 2.0 & 0.01 \\
\hline Lower managers and professionals & 484 & 12.1 & 12.1 & 12.1 & NS \\
\hline Intermediate occupations & 271 & 6.8 & 4.5 & 8.8 & 0.01 \\
\hline Self employed & 540 & 13.5 & 18.1 & 9.3 & 0.01 \\
\hline Smaller supervisors, craft, and related occupations & 278 & 7.0 & 10.8 & 3.5 & 0.01 \\
\hline Semi-routine occupations & 499 & 12.5 & 9.0 & 15.7 & 0.01 \\
\hline Routine occupations & 676 & 16.9 & 13.9 & 19.7 & 0.01 \\
\hline Unemployed & 138 & 3.5 & 3.7 & 3.3 & NS \\
\hline Others (e.g. retired, students, housewives) & 923 & 23.1 & 20.1 & 25.8 & 0.01 \\
\hline \multicolumn{6}{|l|}{ Psychological stress } \\
\hline Never/almost never confident handling personal problems & 212 & 5.3 & 4.1 & 6.5 & 0.001 \\
\hline Never/almost never felt things going my way & 365 & 9.2 & 6.9 & 11.3 & 0.001 \\
\hline Often/very often unable to control important things in life & 373 & 9.4 & 7.0 & 11.7 & 0.001 \\
\hline Often/very often felt difficulties could not be overcome & 280 & 7.0 & 5.1 & 8.8 & 0.001 \\
\hline \multicolumn{6}{|l|}{ Social support } \\
\hline None to count for instrumental support & 165 & 4.1 & 3.5 & 4.7 & NS \\
\hline None to count for emotional support & 320 & 8.0 & 9.1 & 7.0 & 0.05 \\
\hline
\end{tabular}

were used to examine the associations between occupational class, psychosocial variables, and smoking. In order to examine the role of psychosocial factors in explaining the relation between unemployment and smoking, three logistic regression models were developed. The first model studied the relationship between unemployment and smoking controlling for demographic factors. The second model included psychosocial factors into the analysis. The third model assessed the relationship of interest when other socioeconomic factors were introduced into the equation. The significance of interactions between unemployment, psychosocial factors, and socioeconomic variables were tested by including interaction terms in the models.

\section{RESULTS}

Table 1 shows the distribution of the major variables of interest for a total sample of 4002 adults with an average (SD) age of 45.7 (16.8) years. A detailed description of the sociodemographic characteristics of the sample is reported elsewhere. ${ }^{25}$ The overall prevalence of daily smoking was $22.2 \%(\mathrm{n}=889)$ with relevant differences among males and females $(26.2 \% v 18.6 \%$; $<<0.001)$. Looking at the distribution of respondents divided into the eight NS-SEC categories, there were no substantial sex differences in terms of unemployment status. The proportion of males who worked as higher managers and professionals was substantially higher than the same proportion for females $(7.9 \% \vee 2.0 \%$; $\mathrm{p}<0.001)$, who were more likely to occupy intermediate occupations compared to males $(8.8 \% \vee 4.5 \%$; $\mathrm{p}<0.001)$. Males were also more likely than females to be self employed $(18.1 \% \vee 9.1 \% ; \mathrm{p}<0.001)$ as well as to work as supervisors and in craft occupations ( $10.8 \%$ v 3.5\%; p < 0.001). Finally, a higher proportion of females compared to males was working in routine $(19.7 \% \vee 13.9 \% ; \mathrm{p}<0.001)$ and semi-routine occupations ( $15.7 \%$ v 9.0\%; $\mathrm{p}<0.001)$.

When considering psychosocial factors, consistent with previous data in the literature, females reported a higher level of stress than males. ${ }^{26}$ A higher percentage of females never or almost never felt "confident in handling personal problems" $(6.5 \%$ v 4.1\%; $\mathrm{p}<0.001)$ and that "things were going their way" $(11.3 \% v 6.3 \% ; \mathrm{p}<0.001)$. Also females were more likely than males to declare that often or very often they felt "unable to control important things in life" ( $11.7 \%$ v 7.0\%; $\mathrm{p}<0.001$ ) and that "difficulties piled up so that they could not be overcome" $(8.8 \%$ v 5.1\%; p < 0.001$)$. With regard to instrumental support, a smaller proportion of males had no one they could count on for help with daily activities such as grocery shopping and housework, compared to females, but the difference was not significant. However, a higher proportion of males reported having no one to talk to about a personal problem or discuss a difficult life decision, compared to females $(9.1 \% \vee 7.0 \%$; p $<0.05)$.

Figure 1 shows the distribution of smoking across occupational classes. Cigarette smoking was significantly associated with the NS-SEC scheme (linear by linear association $=8.39$; $\mathrm{df}=1$; $\mathrm{p}<0.01$ ); however, this relationship was due to the effect of unemployment. In fact, when unemployment was excluded from the analysis, the relationship was no longer significant (data not shown). Unemployed people were more likely to smoke than all other occupational categories ( $42.8 \% v 25.1 \%$ or less), while higher and lower managerial levels and professionals reported the lowest prevalence of tobacco smoking (18.7\% and 19.3\%). However, with the exception of the unemployed, small employers and self employed workers were more likely to smoke compared to those in the lower occupational classes.

Figure 2 shows that occupational class was associated with psychological stress, as demonstrated by the significant associations between the NS-SEC scheme and the four stress items "things are going my way" (linear by linear association $=12.29 ; \mathrm{df}=1 ; \mathrm{p}<0.001)$, "difficulties are piling up that could not be overcome" (linear by linear association $=11.41 ; \mathrm{df}=1 ; \mathrm{p}<0.001)$, "confident in dealing with personal problems" (linear by linear association = 9.33; $\mathrm{df}=1 ; \mathrm{p}<0.01$ ), and "inability to control important things in life" (linear by linear association $=6.33 ; \mathrm{df}=1 ; \mathrm{p}<0.05)$. Among the eight NS-SEC categories, unemployed people were much more likely than 


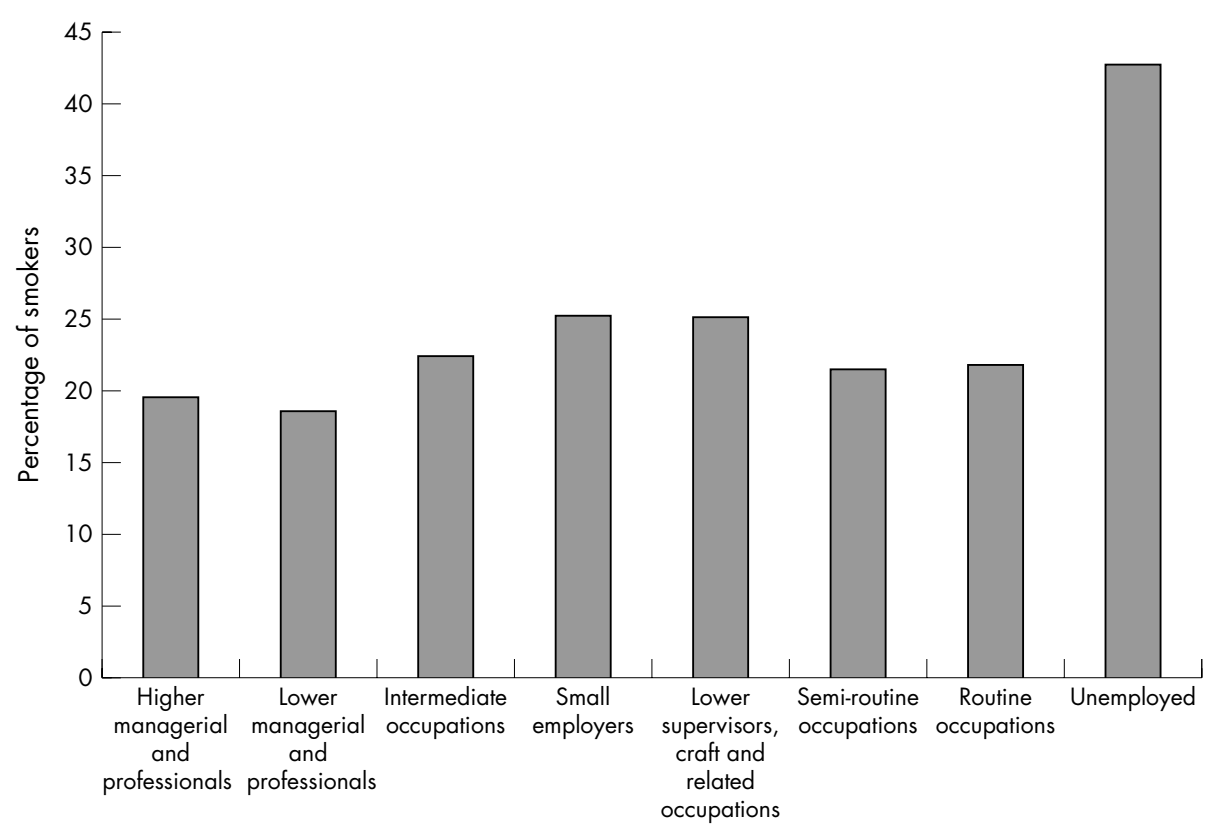

Figure 1 Occupational class and smoking.

NS-SEC occupational class

any other occupational category to be psychologically distressed while managers were the least psychologically distressed.

Figure 3 represents the distribution of social isolation across the eight NS-SEC occupational classes. Occupational class was not associated with emotional and instrumental support. The social gradient of social support was not linear and consistent across different occupational classes. Small employers were the most socially isolated individuals among the eight NS-SEC classes (13\% $v 10 \%$ or less). People employed in intermediate occupations were the least likely to be socially isolated. Interestingly, very few people in the unemployed category reported having no one to count on for instrumental support, but almost one fifth of them reported an absence of emotional support.

Table 2 shows the results of the logistic regression models on smoking with socioeconomic, demographic, and psychosocial factors as covariates. Model 1 shows that occupational class was significantly associated with smoking only when considering the unemployed and self employed and categories. The odds of smoking among the unemployed were 2.78 times ( $95 \%$ confidence interval (CI) 1.68 to 4.62 ) greater than that of higher managers and professionals controlling for demographics. A similar but weaker relationship was seen for the self employed (odds ratio (OR) 1.52, 95\% CI 1.01 to 2.30). A series of demographic factors were significantly

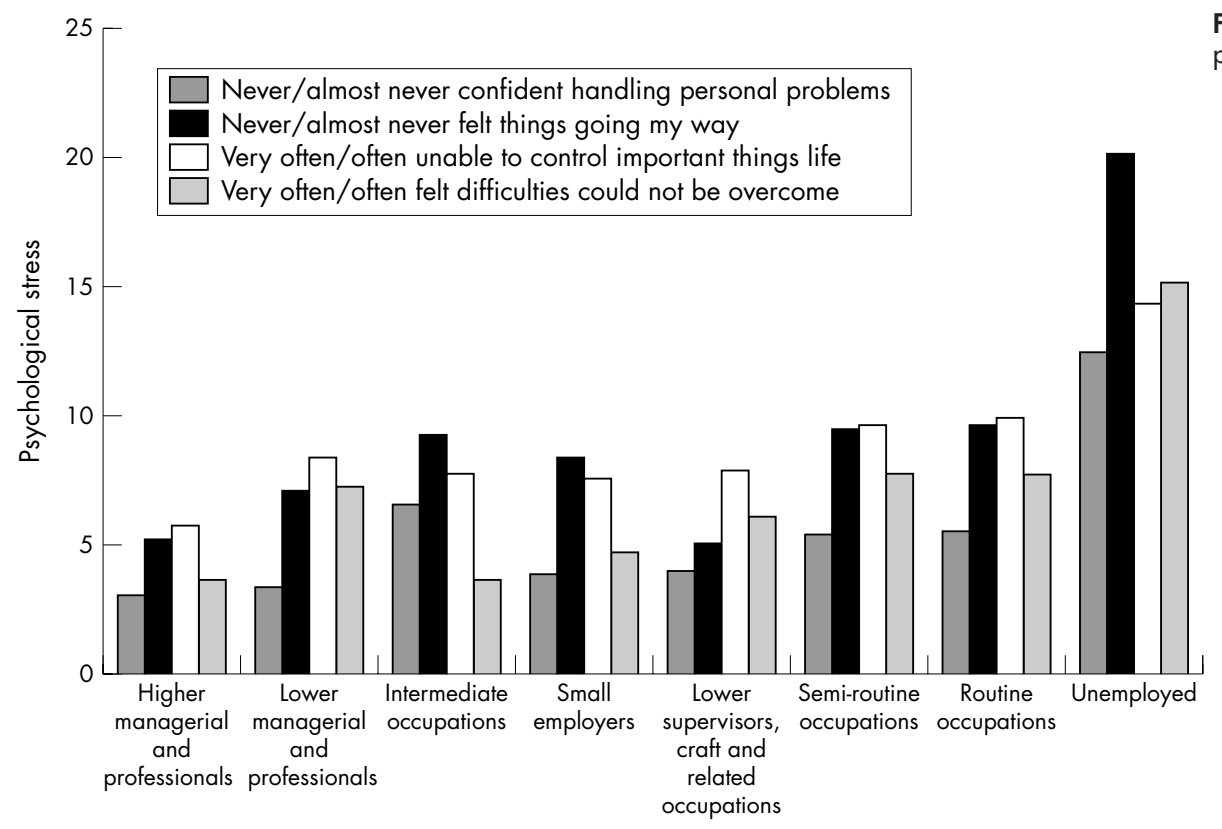

Figure 2 Occupational class and psychosocial factors.

NS-SEC occupational class 


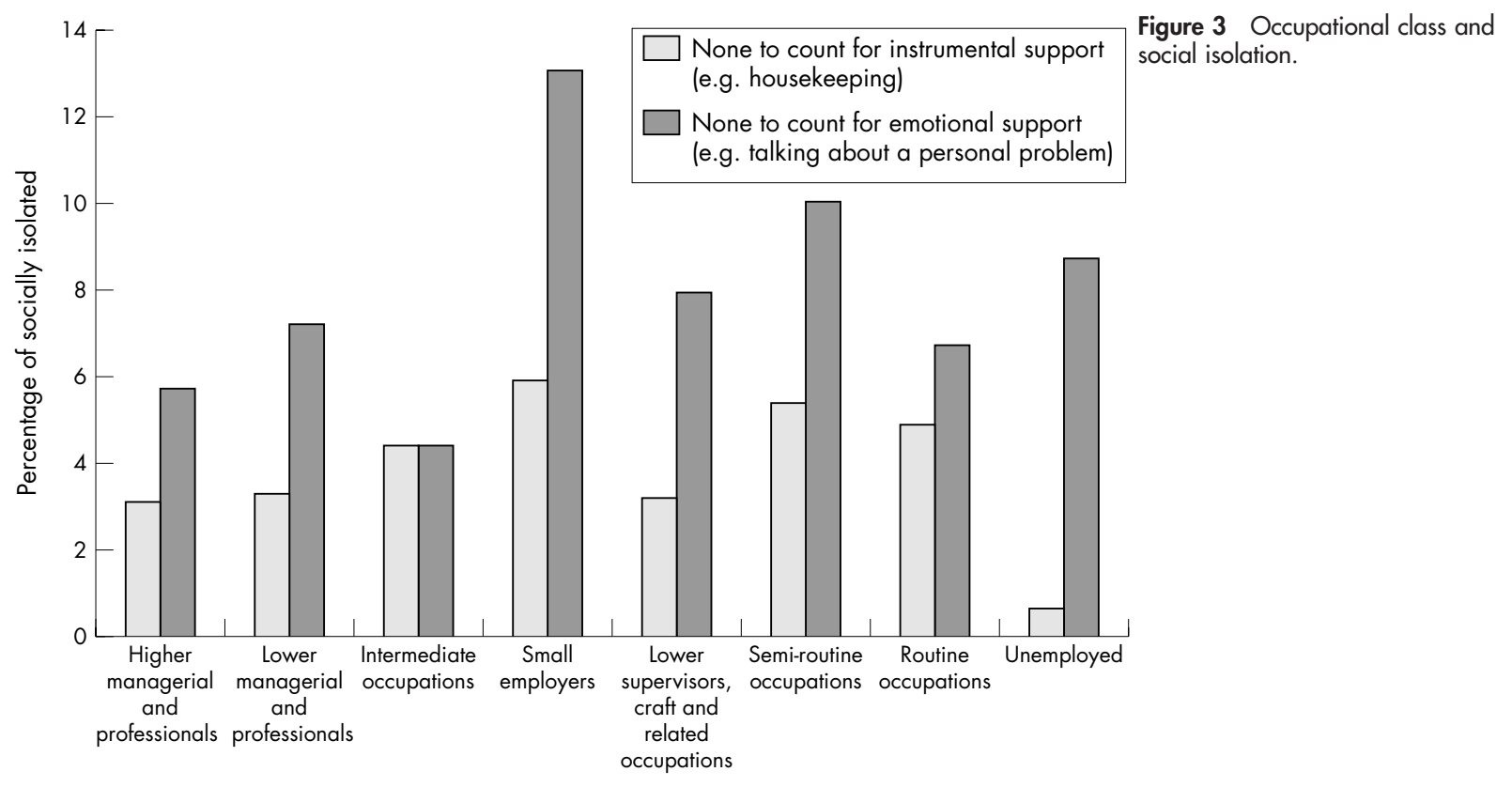

NS-SEC occupational class

associated with smoking including marital status, sex, age, and place of birth. The odds of smoking among people who are not married was 1.54 times (95\% CI 1.23 to 1.91 ) higher than that of those who are married. The odds of smoking among males were 1.41 times (95\% CI 1.18 to 1.70 ) higher than that of females. Smoking decreased with age: the odds of smoking among those aged 18-35 were 2.77 times (95\% CI 1.95 to 3.93 ) higher than that of the elderly. Finally, place of birth was a significant predictor of smoking controlling for demographic, socioeconomic, and psychosocial variables. The odds of smoking for those who were born outside the Veneto region were 1.63 times (95\% CI 1.27 to 2.09 ) higher than that of respondents who were born in Veneto.

Model 2 indicates that when social support and psychological stress were entered into the model, the coefficient for the relationship between unemployment and smoking remained significant, but was reduced by about $20 \%$ (from OR $2.78,95 \%$ CI 1.68 to 4.62 , to OR $2.41,95 \%$ CI 1.43 to 4.05 ). Such a figure indicates an important mediating effect. The inability to control important things in life (OR 1.36, 95\% CI 1.09 to 1.70 ) and lack of emotional support were associated with smoking (OR 1.46, 95\% CI 1.07 to 1.98 ).

Model 3 shows that socioeconomic factors, to the extent they are captured by the survey items available, weakened but did not explain away the association between unemployment and smoking that remained strongly significant (OR 2.23 , $95 \%$ CI 1.28 to 3.88 ). Among other socioeconomic factors, housing tenure and educational attainment were significant predictors of smoking when controlling for occupational class, residential density, car ownership, demographics, and psychosocial variables. The odds of smoking among those who did not own their house was 1.37 times (95\% CI 1.08 to 1.74 ) greater than the odds of those who owned their house. Unexpectedly, the odds ratio of smoking among those with elementary school or less was 0.52 (95\% CI 0.28 to 0.96 ) when using some college or university degree as a reference group.

We also fitted interaction terms to examine whether the association between unemployment and smoking varied between relevant psychosocial and socioeconomic subgroups.
No interaction was found for inability to control important things in life, emotional isolation, and housing tenure.

\section{DISCUSSION}

Results of this study confirm previous findings in the literature regarding the relationship between unemployment and smoking. ${ }^{27}$ They are also consistent with results on the association between unemployment and stress. ${ }^{112829}$ The study adds to the previous literature by showing that unemployment may have not only a direct effect on smoking, but also an indirect effect mediated by psychosocial factors such as the inability to control important matters in life and emotional isolation. Previous contributions identified perceived control as a major explanatory factor for health inequality ${ }^{30-34}$ and emphasised the role of emotional support as a stress buffering mechanism. ${ }^{17}$ However, we are not aware of any study showing that psychosocial factors mediate the relationship between unemployment and smoking.

These results must be interpreted with caution. Given the data were cross sectional, firm conclusions cannot be drawn regarding the causal pathways connecting unemployment and smoking. Although multivariate analyses suggest that psychosocial factors partially explain the effect of unemployment on smoking, it is important to note that there may be other explanations for the study's findings. One explanation is that smoking and stress are influenced by low socioeconomic status or the cumulative exposure to social and economic circumstances, beginning from the early childhood and continuing through to the later stages of life. ${ }^{35}$ However, in this study we have adjusted for the potential confounding effects of socioeconomic background factors including education, housing tenure, car ownership, and residential density. A second explanation, called the selection hypothesis, is that smoking itself increases unemployment. ${ }^{36-38}$ In this study, we could not adjust for health behaviour before unemployment; however, a previous cohort study has demonstrated that even when controlling for this factor, an independent effect of unemployment on smoking remains. ${ }^{10}$ Future longitudinal cohort studies are needed to either confirm or reject the relationships shown in this work and 
Table 2 Logistic regression models on smoking

\begin{tabular}{|c|c|c|c|c|c|c|}
\hline & \multicolumn{6}{|l|}{ Smoking } \\
\hline & \multicolumn{2}{|l|}{ Model 1} & \multicolumn{2}{|l|}{ Model 2} & \multicolumn{2}{|l|}{ Model 3} \\
\hline & OR & $95 \% \mathrm{Cl}$ & OR & $95 \% \mathrm{Cl}$ & OR & $95 \% \mathrm{Cl}$ \\
\hline \multicolumn{7}{|l|}{ Occupational class } \\
\hline Higher managers and professionals & 1.00 & Reference & 1.00 & Reference & 1.00 & Reference \\
\hline Lower managers and professionals & 1.02 & 0.66 to 1.57 & 0.95 & 0.61 to 1.47 & 1.00 & 0.63 to 1.57 \\
\hline Intermediate employees & 1.33 & 0.83 to 2.13 & 1.21 & 0.75 to 1.95 & 1.20 & 0.72 to 1.97 \\
\hline Small employers & $1.52^{*}$ & 1.01 to 2.30 & 1.39 & 0.91 to 2.11 & 1.30 & 0.84 to 2.02 \\
\hline Lower supervisors & 1.38 & 0.87 to 2.17 & 1.34 & 0.85 to 2.13 & 1.28 & 0.79 to 2.08 \\
\hline Semi-routine employees & 1.29 & 0.84 to 1.98 & 1.23 & 0.80 to 1.90 & 1.16 & 0.70 to 1.76 \\
\hline Routine employees & 1.30 & 0.77 to 1.82 & 1.27 & 0.83 to 1.92 & 1.15 & 0.73 to 1.80 \\
\hline Unemployed & $2.78^{* * *}$ & 1.68 to 4.62 & $2.41^{* * *}$ & 1.43 to 4.05 & $2.23^{* *}$ & 1.28 to 3.88 \\
\hline \multicolumn{7}{|l|}{ Sex } \\
\hline Female & 1.00 & Reference & 1.00 & Reference & 1.00 & Reference \\
\hline Male & $1.41^{\star * *}$ & 1.18 to 1.70 & $1.44^{* * *}$ & 1.19 to 1.74 & $1.39^{* * *}$ & 1.15 to 1.69 \\
\hline \multicolumn{7}{|l|}{ Age (years) } \\
\hline $65+$ & 1.00 & Reference & 1.00 & Reference & 1.00 & Reference \\
\hline $55-64$ & $2.36^{* * *}$ & 1.70 to 2.02 & $2.41^{* \star *}$ & 1.72 to 3.36 & $2.21^{* * *}$ & 1.53 to 3.19 \\
\hline $35-54$ & $2.53^{\star * *}$ & 1.80 to 3.55 & $2.77^{\star * *}$ & 1.96 to 3.93 & $2.48^{* * *}$ & 1.63 to 3.77 \\
\hline $18-34$ & $2.77^{* * *}$ & 1.95 to 3.93 & $2.89^{* * *}$ & 2.02 to 4.13 & $2.54^{\star * *}$ & 1.66 to 3.87 \\
\hline \multicolumn{7}{|l|}{ Marital status } \\
\hline Married/living with a partner & 1.00 & Reference & 1.00 & Reference & 1.00 & Reference \\
\hline Not married & $1.54^{* * *}$ & 1.23 to 1.91 & $1.45^{\star \star *}$ & 1.15 to 1.81 & $1.52^{* \star *}$ & 1.20 to 1.93 \\
\hline \multicolumn{7}{|l|}{ Place of birth } \\
\hline Veneto & 1.00 & Reference & 1.00 & Reference & 1.00 & Reference \\
\hline Outside Veneto & $1.63^{\star * * *}$ & 1.27 to 2.09 & $1.62^{* \star *}$ & 1.25 to 2.09 & $1.62^{\star * *}$ & 1.24 to 2.11 \\
\hline \multicolumn{7}{|l|}{ Confident handling personal problems } \\
\hline Very often/often & & & 1.00 & Reference & 1.00 & Reference \\
\hline Never/almost never/sometimes & & & 0.91 & 0.70 to 1.19 & 0.93 & 0.71 to 1.22 \\
\hline \multicolumn{7}{|l|}{ Felt that things going my way } \\
\hline Very often/often & & & 1.00 & Reference & 1.00 & Reference \\
\hline Never/almost never/sometimes & & & 1.16 & 0.93 to 1.44 & 1.13 & 0.90 to 1.42 \\
\hline \multicolumn{7}{|l|}{ Unable to control important things in life } \\
\hline Never/almost never & & & 1.00 & Reference & 1.00 & Reference \\
\hline Very often/often/sometimes & & & $1.36^{* *}$ & 1.09 to 1.70 & $1.39^{* *}$ & 1.11 to 1.75 \\
\hline \multicolumn{7}{|l|}{ Felt difficulties could not be overcome } \\
\hline Never/almost never & & & 1.00 & Reference & 1.00 & Reference \\
\hline Very often/often/sometimes & & & 1.20 & 0.94 to 1.65 & 1.23 & 0.97 to 1.71 \\
\hline \multicolumn{7}{|l|}{ People to count on for instrumental support } \\
\hline At least one person & & & 1.00 & Reference & 1.00 & Reference \\
\hline & & & 0.93 & 0.60 to 1.46 & 0.94 & 0.59 to 1.48 \\
\hline \multicolumn{7}{|l|}{ People to count on for emotional support } \\
\hline At least one person & & & 1.00 & Reference & 1.00 & Reference \\
\hline None & & & $1.46^{* *}$ & 1.07 to 1.98 & $1.45^{*}$ & 1.06 to 1.99 \\
\hline \multicolumn{7}{|l|}{ Education } \\
\hline Some college/university degree & & & & & 1.00 & Reference \\
\hline Secondary school & & & & & 1.16 & 0.87 to 1.56 \\
\hline Primary school & & & & & 0.94 & 0.66 to 1.34 \\
\hline Elementary school or less & & & & & $0.52^{*}$ & 0.28 to 0.96 \\
\hline Residential density & & & & & & \\
\hline More than 1 room/person & & & & & 1.00 & Reference \\
\hline $1 \mathrm{room} /$ person or less & & & & & 1.09 & 0.90 to 1.31 \\
\hline Car ownership & & & & & & \\
\hline Yes & & & & & 1.00 & Reference \\
\hline No & & & & & 0.73 & 0.42 to 1.35 \\
\hline Housing tenure & & & & & & \\
\hline Yes & & & & & 1.00 & Reference \\
\hline No & & & & & $1.37^{\star *}$ & 1.08 to 1.74 \\
\hline Constant & $0.56^{* * *}$ & & $0.50^{* * *}$ & & $0.39^{* * *}$ & \\
\hline
\end{tabular}

Significant difference: ${ }^{*} \mathrm{p}<0.05 ;{ }^{* *} \mathrm{p}<0.01 ;{ }^{* * *} \mathrm{p}<0.001$.

Data were weighted to adjust for the number of adults within each household, over sampling of adults living in low density population provinces and under sampling of unemployed adults in the Veneto region.

$\mathrm{Cl}$, confidence interval; OR, odds ratio.

analyse psychosocial pathways connecting unemployment and smoking. Another limitation of this study is the use of a non-probability sample in the HDSS survey. The use of quota sampling makes it difficult to generalise findings to the general population, even though a comparison of demographic characteristics of the HDSS sample with the 2001 Census $^{39}$ showed that selection biases were very small. Finally, the low response rate achieved in the HDSS survey 2003 may have created substantial opportunities for nonresponse biases. However, given the negligible differences in terms of demographic and socioeconomic characteristics between the HDSS sample and the 2001 Veneto Census, it is possible to conclude that such biases were very small.

Despite the limitations, this is the first research study suggesting that psychosocial factors such as the inability to control life and emotional isolation may be plausible mediators for the relationship. Such results have important implications in terms of health promotion and tobacco control. By identifying the hazardous behavioural and psychosocial effects of unemployment, this study highlights the importance of considering contextual socioeconomic conditions as important risk factors for smoking and stress. 


\section{What this paper adds}

Numerous studies have shown that unemployment is associated with smoking. Smoking has been found to act as a stress reliever as well as being associated with uncontrollable social and economic stressors disproportionately affecting lower occupational classes, including unemployed people.

Our research shows that psychosocial factors such as the inability to control important things in life and emotional isolation seem to be important mediators for the relationship between unemployment and smoking. When considering policy implications, in order to decrease smoking related morbidity and mortality, it is crucial to reduce levels of unemployment, inability to control life, and emotional isolation.

On the one hand, the creation of work opportunities and policies aiming at full employment are essential to promote healthy behaviours and psychosocial wellbeing among the general population. On the other hand, socioeconomic buffering mechanisms such as unemployment benefits may be effective strategies to reduce stress and smoking among the unemployed. In addition to proposing individual level interventions, this study suggests that it is crucial to address those socioeconomic forces such as unemployment that influence smoking and stress at the macro level.

\section{ACKNOWLEDGEMENTS}

The HDSS 2003 was supported by the Italian Ministry of Health and the Regional Ministry of Health of Veneto.

\section{Authors' affiliations}

R D Vogli, The University College of London, Department of Epidemiology and Public Health, International Centre for Health and Society, London, UK

M Santinello, The University of Padua, Faculty of Psychology, Department of Development and Social Psychology, Padua, Italy

Competing interests: none declared

\section{REFERENCES}

1 World Health Organization. World health report 2002: reducing risks promoting healthy life. Geneva: World Health Organization, 2002.

2 Doll R, Peto R. The causes of cancer: appendix E. I Natl Cancer Inst 1981;66:1292-305.

3 Peto R, Lopez A, Boreham J, et al. Mortality from tobacco in developed countries: indirect estimates from national vital statistics. Lancet 1992;339:1 1268-78.

4 Waldron I, Lye D. Employment, unemployment, occupation, and smoking. Am J Prev Med 1989;5:142-9.

5 Liira J, Leino-Arjas P. Predictors and consequences of unemployment in construction and forest work during a 5-year follow-up. Scand J Work Environ Health 1999;25:42-9.

6 Hammarstrom A. Health consequences of youth unemployment. Public Health 1994;108:403-12.

7 Osler T. Smoking habits in Denmark from 1953 to 1991: a comparative analysis of results from three nationwide health surveys among adult Danes in 1953-54, 1986-1987 and 1990-91. Int J Epidemiol 1992;21:862-71.

8 Hammarstrom A, Janlert U. Early unemployment can contribute to adult health problems: results from a longitudinal study of school leavers. J Epidemiol Community Health 2001;56:624-30.

9 Hammarstrom A, Janlert U. Unemployment: an important predictor for future smoking: a 14-year follow up study of school leavers. Scand J Public Health 2003;31:229-32.
10 Montgomery S, Cook D, Bartley M, et al. Unemployment, cigarette smoking, alcohol consumption and body weight in young British men. Eur J Public Health 1998;8:21-27.

11 Thomas C, Benzeval M, Stansfeld S. Employment transitions and mental health: an analysis from the British household panel survey. J Epidemiol Community Health 2005;59:243-9.

12 Jarvis $M$, Wardle J. Social patterning of individual health behaviours: the case of cigarette smoking. In: Marmot M, Wilkinson R, eds. Social determinants of health. London: Oxford University Press, 1999.

13 Metcalfe C, Smith G, Wadsworth E, et al. A contemporary validation of the Reeder stress inventory. Br J Health Psychol 2003;8:83-94.

14 Bradstock K, Forman $\mathrm{M}$, Binkin N, et al. Alcohol use and health behavior lifestyles among U.S. women: the behavioral risk factor surveys, Addictive Behaviors 1988;13:61-71.

15 Jarvis M. Smoking and stress. In: Stansfeld S, Marmot M, eds. Stress and the heart. London: BMJ Books, 2002.

16 Cohen S, Underwood L, Gottlieb B. Social support measurement and intervention: a guide for health and social scientists. New York: Oxford University Press, 2000.

17 Kieselbach T. Long-term unemployment among young people: the risk of social exclusion. Am J Community Psychol 2003;32:69-76.

18 Daniel M, Cargo M, Lifshay J, et al. Cigarette smoking, mental health and social support: data from a northwestern First Nation. Can J Public Health 2004;95:45-9.

19 Centers for Disease Control and Prevention. Behavioural risk factor surveillance system (BRFSS) questionnaire 2003. Bethesda, Maryland: CDC, 2003.

20 Cohen S, Williamson G. Perceived stress in a probability sample of the United States. In: Spacapam S, Oskamp S, eds. The social psychology of health: Claremont symposium on applied social psychology. Newbury Park, California: Sage, 1988

21 Seeman T, Berkman L. Structural characteristics of social networks and their relationships with social support in the elderly: who provides support. Soc Sci relationships with social $1988 ; 26: 737-49$.
Med

22 Chandola T, Jenkinson C. The new UK national statistics socio-economic classification (NS-SEC): investigating social class differences in self-reported health status. J Public Health Med 2000;22:182-90.

23 Rose D, Pevalin D. The national statistics socio-economic classification: unifying official and sociological approaches to the conceptualisation and measurement of social class. Colchester: University of Essex, 2001.

24 SPSS. Statistical package for social sciences. Chicago: SPSS Inc, 2003.

25 De Vogli R, Gnesotto R. Sistema di Sorveglianza dei Determinanti di Salute (SSDS). Regional Ministry of Health of Veneto and the Italian Ministry of Health, 2003

26 Cohen S, Kessler R, Gordon L. Measuring stress: a guide for health and social scientists. New York: Oxford University Press, 1997.

27 Bartley M. Unemployment and ill health: understanding the relationship. J Epidemiol Community Health 1994:48:333-7.

28 Sen A. Inequality, unemployment and contemporary Europe. International Labour Review 1977;136(2).

29 Bjarnason T, Sigurdardottir T. Psychological distress during unemployment and beyond: social support and material deprivation among youth in six northern European countries. Soc Sci Med 2003;56:973-85.

30 Syme S. Control and health: a personal perspective. In: Steptoe A, Appels A, eds. Stress, personal control and health. London: Wiley, 1989.

31 Marmot $\mathrm{M}$, Bosma H, Hemigway H, et al. Contribution of job control and other risk factors to social variations in coronary heart disease incidence. Lancet 1997;349:235-9.

32 Bosma H, Schrijvers C, Mackenbach J. Socioeconomic inequalities in mortality and importance of perceived control. BMJ 1999;319:1469-70.

33 Bosma $\mathrm{H}$, Marmot M, Hemingway $\mathrm{H}$, et al. Low job control and risk of coronary heart disease in Whitehall II (prospective cohort) study. BMJ 1997;314:558.

34 Malinauskiene V, Theorell T, Grazuleviciene R, et al. Low job control and myocardial infarction risk in the occupational categories of Kaunas. $J$ Epidemiol Community Health 2004;58:131-5.

35 Gilman S, Abrams D, Buka S. Socioeconomic status over the life course and stages of cigarette use: initiation, regular use, and cessation. J Epidemiol Community Health 2003;57:802-8.

36 Cook D. A critical view of the unemployment and health debate. Statistician 1985;34:73-82.

37 Wagstaff A. Unemployment and health: some piffalls for the unwary. Health Trends 1986;18:79-81.

38 Clausen B, Bjorndal A, Hiort P. Health and re-employment in a two year follow-up of long term unemployed. I Epidemiol Community Health 1993:47:14-18.

39 De Vogli R. Socioeconomic determinants of healthy lifestyles: does psychosocial stress matter? PhD dissertation. University of California Los Angeles, 2003. 